\title{
Colon Adenosquamous Carcinoma
}

National Cancer Institute

\section{Source}

National Cancer Institute. Colon Adenosquamous Carcinoma. NCI Thesaurus. Code C5491.

An unusual colon carcinoma characterized by the presence of glandular and squamous carcinomatous components. The two carcinomatous components may be admixed within the tumor, or the two may appear separately in different areas. 